\title{
Three dimensional measurements of asphaltene deposition in a transparent micro-channel
}

\author{
Y. Zhuang ${ }^{\mathrm{a}}$, A. Goharzadeh ${ }^{\mathrm{a}, *}$, Y.J. Lin ${ }^{\mathrm{b}}$, Yit F. Yap ${ }^{\mathrm{a}}$, J.C. Chai ${ }^{\mathrm{a}, 1}$, N. Mathew ${ }^{\mathrm{c}}$, F. Vargas $^{\mathrm{b}}$, \\ Sibani L. Biswal ${ }^{\text {b }}$ \\ a Department of Mechanical Engineering, The Petroleum Institute, Abu Dhabi, United Arab Emirates \\ ${ }^{\mathrm{b}}$ Department of Chemical and Biomolecular Engineering, Rice University, TX, USA

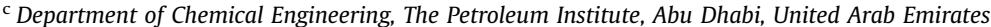

\section{A R T I C L E I N F O}

Article history:

Received 6 December 2015

Received in revised form

15 March 2016

Accepted 24 March 2016

Available online 28 March 2016

Keywords:

Asphaltene deposition

Micro-channels

3D digital microscopy

\begin{abstract}
A B S T R A C T
This study describes a novel experimental approach to directly measure the thicknesses of asphaltene deposits in micro-channels. The thickness of the asphaltene deposit is estimated using a visualization technique based on 3D digital microscopy. The working fluid is a mixture of n-heptane and dead oil. Induced by the addition of n-heptane, the asphaltenes present in crude oil phase separate at ambient temperature to form aggregates of asphaltene-rich phase. Part of the asphaltene aggregates deposit on the walls of the transparent micro-channel. A two-dimensional profile of the deposit across the channel at selected axial sections is measured. The influences of injection mixture volume on the growth of the thickness of deposited asphaltenes is investigated using two experimental conditions, (i) varying elapsed time at constant flow rate and (ii) increasing the flow rate at a constant elapsed time. In both cases the deposit thickness of asphaltene $(\delta)$ increases with the total injection volume $(V)$. The experimental results obtained in this work provide new insights into the deposition process at the micro-scale level, which can be used to facilitate the development of more accurate numerical model for this application.
\end{abstract} (c) 2016 Elsevier B.V. All rights reserved.

\section{Introduction}

During the process of oil production, transportation and refinery, asphaltene aggregates are formed at specific temperature and pressure conditions and deposit in the wellbore and the nearwellbore region. This deposition can cause formation damage in reservoirs, blockage in wellbores or even problem in separators, pumps, pipelines, heat exchangers and other equipment (Akbarzadeh et al., 2012). Therefore, understanding the mechanisms of asphaltene disposition has direct impact on oil production and attracts considerable attention in petroleum engineering (Papadimitriou et al., 2007; Buckley, 2012), with the main objective of preventing the asphaltene deposition. Combining effect of both thermodynamic and hydrodynamic parameters, coupled with chemical reactions, forces the deposition process to be extremely difficult to model, predict and prevent (Hammami et al., 2000; Sheu et al., 2007). To investigate the influence of hydrodynamic effects on asphaltene deposition, such as interaction between

\footnotetext{
* Corresponding author at: Department of Mechanical Engineering, The Petroleum Institute, Abu Dhabi, United Arab Emirates.

E-mail address: agoharzadeh@pi.ac.ae (A. Goharzadeh).

${ }^{1}$ Current address: School of Computing \& Engineering, University of Huddersfield, Huddersfield, UK.
}

asphaltene particles and solid walls, the rate of asphaltene deposition, or shear stress of the deposits, micro-scale experiments are widely used and represent novel and suitable systems (Schneider et al., 2013; Hu et al., 2014). The utilizations of microchannels offer the advances in studying interfacial properties and intrinsic asphaltene behaviors in straight micro-channels (Seifried et al., 2013) and micro-porous media (Hu et al., 2014).

In previous experimental studies, micro-scale devices have been used to quantify asphaltene deposits and measure the deposition rate in stainless steel capillary tubes (Broseta et al., 2000; Wang et al., 2004; Nabzar and Aguiléra, 2008; Hoepfner et al., 2013), transparent glass capillary tubes or micro-channels (Boek et al., 2008, 2009; Lawal et al., 2012; Buckley, 2012).

Both homogeneous and non-homogeneous deposits have been reported depending on experimental conditions. Table 1 shows a summary of experimental tests with corresponding experimental conditions.

Broseta et al. (2000) reported asphaltene deposition using continuous flow in a capillary tube. Their experiments were conducted in a temperature- and pressure- controlled system in which pressure drops were measured and the deposit depths were calculated from the change in pressure drop as a result of asphaltene deposition. They observed that the rate of deposition increased with the distance from deposition onset. Nabzar and 
Table 1

A summary of experimental tests with corresponding experimental conditions.

\begin{tabular}{|c|c|c|c|c|}
\hline Ref. & Characteristics length $(\mu \mathrm{m})$ & Flow rate $(\mathrm{ml} / \mathrm{min})$ & Velocity $(\mathrm{m} / \mathrm{s})$ & Reynolds number \\
\hline Broseta et al. (2000) & 250 & $0.1-10$ & $0.034-3.4$ & $\begin{array}{l}\text { Crude Oil B: 0.998-99.8 } \\
\text { Crude Oil F: } 0.144-14.4\end{array}$ \\
\hline Wang et al. (2004) & 508 & $0-3.33$ & 0.274 & - \\
\hline Nabzar and Aguiléra (2008) & $116-520$ & $0.25-4$ & $0.039-1.577$ & $\begin{array}{l}\text { Weyburn: } 4.3-779 \\
\text { Arabian Light: } 1.5-277 \\
\text { Hassi Messaoud: } 3.9-708\end{array}$ \\
\hline Boek et al. (2008), (2009) & 91 & $0.002-0.01$ & $0.0051-0.0256$ & $<<1$ \\
\hline Lawal et al. (2012) & 320 & $0.005-0.06$ & $0.001-0.012$ & $<0.5$ \\
\hline Seifried et al. (2013) & 91 & 0.005 & $0.0012-0.0064$ & 0.8 \\
\hline Buckley (2012) & 36 & 0 & 0 & 0 \\
\hline Hoepfner et al. (2013) & 254 or 762 & 0.6 & $0.022-0.197$ & $\begin{array}{l}\text { A:0.18-4.96 } \\
\text { WY: } 0.62-16.7\end{array}$ \\
\hline
\end{tabular}

Aguiléra (2008) used similar capillary tubes and proposed general scaling laws. They observed that the deposit thickness was increasing rapidly with the reduction of the shear rate. Lawal et al. (2012) visualized the asphaltene deposition in transparent cylindrical glass capillary tubes and correlated the deposition patterns with deposit thicknesses deduced from pressure drop measurements.

In above experimental studies, empirical models were developed to predict the thickness of the asphaltene deposits based on indirect measurement techniques where the assumption of uniform deposit thickness was the precondition. However recent experiments based on flow visualization showed that the homogeneous deposition process hypothesis may not be valid. To visualize asphaltene deposition processes, experiments using glass setups were carried out by Boek et al. (2008), (2009) and Seifried et al. (2013). The asphaltene deposition was directly visualized in a transparent rectangular micro-channel, as a function of the distance from the capillary entrance. They concluded that the distribution of deposits was not uniform in space, which decreased from the capillary entrance and also changed with time for a fixed flow rate. Hoepfner et al. (2013) conducted a series of experiments with similar mixing conditions that Buckley (2012) has used. They have visualized the highly non-uniform axial deposit profile using scanning electron microscope (SEM), and found that the pressure drop increased with increasing the elapsed time during the flow tests.

Wang et al. (2004) investigated deposition rate process. They observed that deposition rate was independent of tube length and flow rate and relied on mixture super-saturation of oil and n-alkanes. Jamialahmadi et al. (2009) have used non-isothermal conditions to estimate the mass of asphaltene deposition by measuring heat transfer coefficient and the thermal resistance of the asphaltene deposit. Their experimental results showed that the rate of deposition was proportional to surface temperature and asphaltene concentration. However, they also observed deposition rate increased when oil velocity was decreased. Seifried et al. (2013) suggested that the asphaltene deposition rate was sensitive to the magnitude of the average mixture velocity at the earlier experimental time. This early asphaltene behavior relied on the flux of particles through the experimental setup. They also found that the influence of flow rate on deposition thickness was almost negligible.

In experimental studies reported in Table 1, indirect measurement techniques have been used to investigate the driving forces in the asphaltene deposition process and estimate the amount of asphaltene deposits in micro-devices. The proposed visualization techniques were mainly applied on studying asphaltene behaviors. However, the whole deposit profiles cannot be measured since the used channels and capillary tubes were closed.

The objective of this study is to present an innovative method, which is still missing in the literature, to directly measure the asphaltene deposit profiles by using a transparent micro-channel coupled with a 3D microscope. The method describing 3D measurement techniques is presented and applied to analyze the influence of total injection volume on asphaltene deposition. Results for the effect of total injection volume on asphaltene deposit thickness are presented using two different experimental conditions. This novel approach has facilitated the development of accurate simulation for the growth of asphaltene deposits.

In what follows, the experimental setup is described first in Section 2. The details of measurement technique are presented in Section 3. Finally, in Section 4, experimental results, validation and discussions on asphaltene deposition are presented.

\section{Experimental methods}

\subsection{Experimental setup}

The experimental setup consists of a vertical transparent microchannel (Fig. 1), a dual-drive syringe pump having two glass syringes, a collection tank and a microscope for flow visualization. The microchannel was fabricated from Plexiglas and had the dimension of $250 \mu \mathrm{m} \times 50 \mathrm{~mm} \times 2 \mathrm{~mm}$ (depth $\times$ length $\times$ width). In this study, the flow direction is from bottom to top. The syringe pump (Cole-Parmer with $106.6 \mathrm{~mL} / \mathrm{min}$ maximum flow rate) is used to mix two fluids (crude oil and n-heptane) together to generate a mixing working fluid flowing at a designed flow rate. Glass syringes (SAMCO, $10 \mathrm{ml}$ ) and microchannel are connected through transparent plastic tubes and a T-junction. Both fluids were injected to the test section using the T-junction. The ratio of working fluids including crude oil and n-heptane is controlled by flow rates via the syringe pump. All experiments were conducted using a fixed injection ratio of crude oil: n-heptane (3:7). The range of flow rates used was between 0.003 and $0.008 \mathrm{ml} / \mathrm{min}$ while the experimental elapsed times from 4 to $14 \mathrm{~h}$ were examined. The temperature of the working fluids is at a constant temperature of $21^{\circ} \mathrm{C}$.

\subsection{Crude oil preparation}

The oil samples used for these studies were found to be highly unstable (i.e., asphaltene aggregates already formed in the crude oil) at the laboratory conditions. These asphaltene aggregates are removed by centrifuging the crude oil for $15 \mathrm{~min}$ at an angular speed of $4000 \mathrm{rpm}$. The absence of major suspended particles was further confirmed by examining the supernatant oil obtained after centrifugation using a Hirox KH7700 digital microscope. The oil sample was then titrated under ambient conditions with an asphaltene precipitant such as n-Heptane. In order to obtain the best 
Zoom of vertical channel with its metallic holder (a) Schematic View

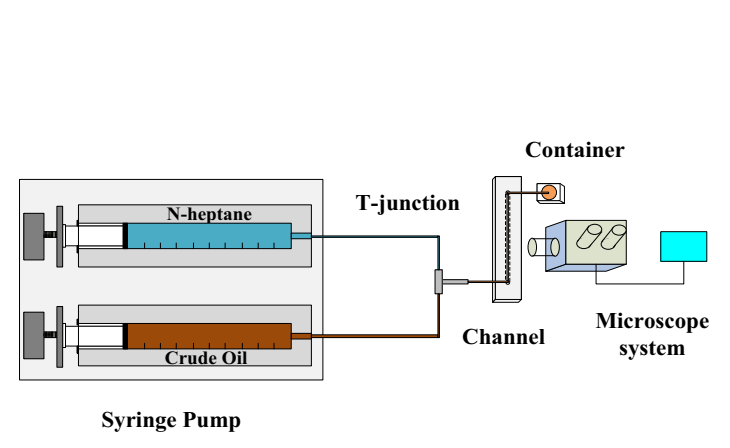

Fig. 1. Experimental setup representing the microchannel in vertical flow condition. (a) Schematic view and (b) Photography.

Table 2

Properties of crude oil

\begin{tabular}{|c|c|c|c|c|c|c|}
\hline API & Density at $20^{\circ} \mathrm{C}\left(\mathrm{g} / \mathrm{cm}^{3}\right)$ & Kinematic viscosity (cSt) & Saturates (wt\%) & Aromatics (wt\%) & Resins (wt\%) & Asphaltenes (wt\%) \\
\hline 36.5 & 0.8412 & 6.505 & 49.9 & 14.2 & 5.6 & 0.4 \\
\hline
\end{tabular}

ratio of oil to asphaltene precipitant, the oil sample was titrated with n-Heptane in the ratios of 0:100 to 100:0 over an aging period of $5 \mathrm{~min}$. Prior to the deposition experiments, the fluid mixture ratio of 3:7, observed under normal microscope, showed sufficient presence of asphaltene particles in the fluid mixture. A subsequent experiment was confirmed that this ratio could create a quantifiable amount of deposits in the micro-channel without blocking the experimental system for at least $14 \mathrm{~h}$ (Zhuang et al., 2015a, 2015b). Properties of the crude oil, obtained from SARA analysis were reported in Table 2. The determination of various components in the crude oil such as Saturates, Aromatics and Resins were characterized by using ASTM D-2007m method and the Asphaltene component was characterized by IP 143 method. The n-heptane precipitant has a density and kinematic viscosity of $0.684 \mathrm{~g} / \mathrm{cm}^{3}$ and $0.647 \mathrm{cSt}$, respectively. Both density and kinematic viscosity of the crude oil were measured by ASTM D-4052 and ASTM D-445, respectively.

\section{Measurement technique using 3D microscopy}

After a continuous deposition experiment, the syringe pump was stopped and all connectors were removed from the microchannel. The microchannel was drained and then dried for $24 \mathrm{~h}$ under laboratory conditions. Once the channel was drained of liquid mixture, the top cover of the channel was removed to facilitate measurements of asphaltene deposit in the channel. The opened microchannel was therefore utilized for deposition thickness measurements. The 3D scanning of asphaltene deposition was achieved by Hirox 3D digital microscope KH-7700 using OL 350 II lens with a maximum magnification lens of $\times 3500$ (Table 3).

The microchannel is placed horizontally under the 3D microscope (Fig. 2a). A small area of the microchannel (1240 by $930 \mu \mathrm{m}^{2}$ ) is selected and viewed under the 3D microscope. The 3D microscope records images at a fixed position in the middle of the channel (at $25 \mathrm{~mm}$ from the entrance). Using the 3D microscope software (Hirox-Real-Time 2D and 3D), the bottom and top
Table 3

Properties of the 3D digital microscope.

\begin{tabular}{ll}
\hline Production name & Hirox KH-7700 \\
\hline Use lens name & MX(G)-5040SZ: OL -350 II \\
Magnification & $350-3500 \times$ \\
Depth of field (Optical) & $762-90 \mu \mathrm{m}$ \\
\hline
\end{tabular}

surfaces of the microchannel are defined by the user before performing a 3D scan of the sample. The microscope starts from the very bottom surface of the sample and moves upward at a constant interval distance until it reaches the very top surface of the sample. Interval distance is determined relative to the distance between the bottom surface and the top surface. Every image taken by the microscope has different zones with fully in and out of focus. The height of each picture is recorded to construct the 3D structure of the deposition. A maximum of 128 images can be taken by the microscope between the bottom and top surfaces. The smallest interval height increment between two images is $0.25 \mu \mathrm{m}$. A reconstructed image of micro-channel in both two and three dimensions are obtained and presented in Fig. $2 b$ and c, respectively. In order to visualize the three dimensional effect, Fig. $2 \mathrm{c}$ is presented using an isometric 3D view of asphaltene layer deposited on the bottom wall of the micro-channel.

\section{Results and discussions}

\subsection{D profile of asphaltene deposit}

Fig. 3a represents a reconstructed image of 128 single images taken between the bottom and top surfaces; each image focused at different vertical positions of the channel. Due to the high magnification of the lens, only a very small region of the micro-channel is visible. The black area represents the deposited layer of asphaltene particles. As it can be observed in the figure, the entire vertical wall of the mini-channel is also covered by a thin layer of 


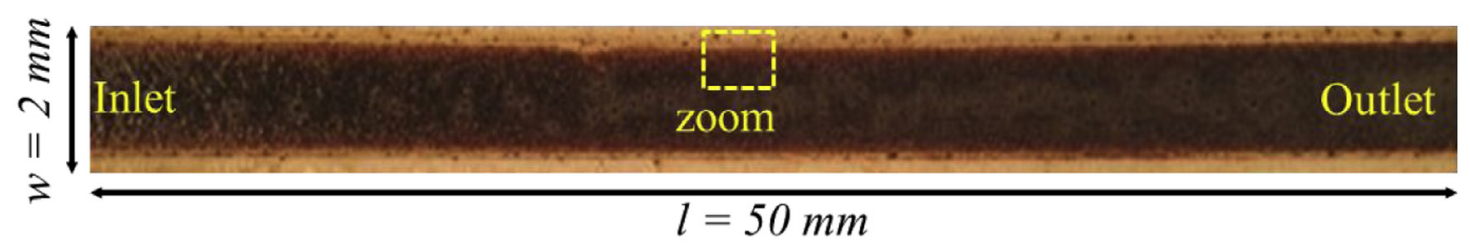

(a) Digital image of the entire channel

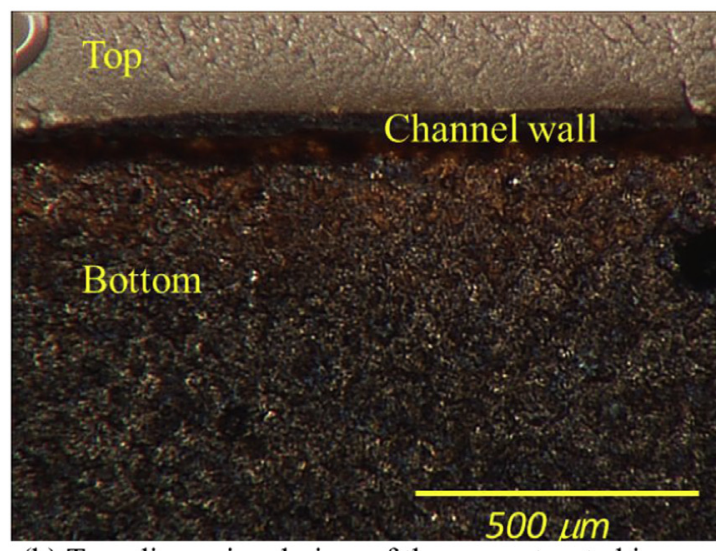

(b) Two dimensional view of the reconstructed image (the magnification is $\times 350$ )

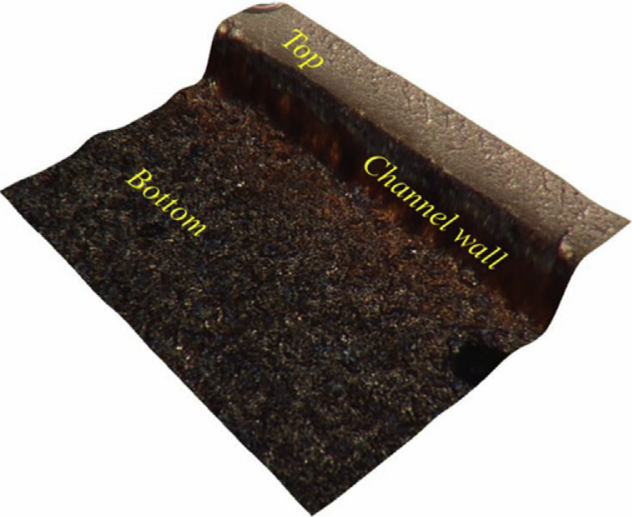

(c) Three dimensional Isometric view of the reconstructed image (the magnification is $\times 350$ )

Fig. 2. Different views of the microchannel with asphaltene deposited on the wall.

asphaltene. In Fig. 3b, the depth of each layer of the asphaltene deposited on the bottom wall is measured and presented using a palette of colors. The legend is given with dimensions in micrometer. Blue and red represent the lowest and the highest vertical positions in the reconstructed image which correspond to the bottom and top surfaces of the channel respectively. Quantitative values of asphaltene deposition can be extracted from Fig. 3 by plotting a 2D profile of the asphaltene deposited on the wall. The average value of the deposited asphaltene layer can be obtained by comparing the measurement with thickness of the empty channel. Fig. 4 represents two pictures of the 3D image of an empty microchannel and a microchannel with deposits. Both pictures were captured in the same location before and after the experiment.

Fig. 4 shows 3D reconstructed image for both empty microchannel (Fig. 4a) and microchannel with asphaltene deposits

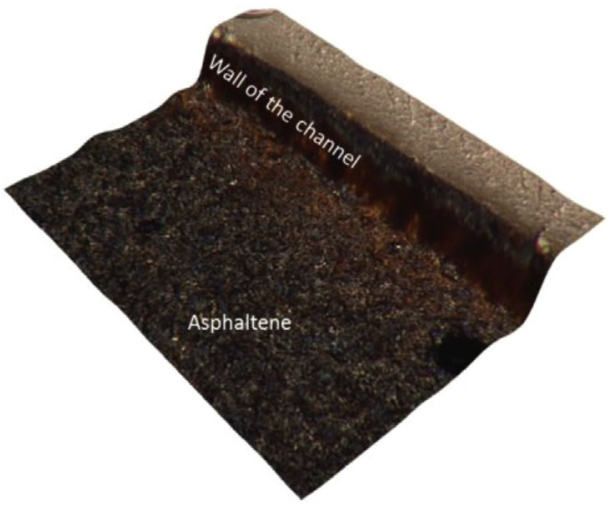

(a) $3 \mathrm{D}$ view of the reconstructed image of asphaltene deposition in a microchannel
(Fig. 4b). In both figures, a vertical and red rectangular plane is indicating the position where a two dimensional deposition profile will be measured. The corresponding two dimensional profiles are shown for empty microchannel and microchannel with deposits in Fig. $5 \mathrm{a}$ and $\mathrm{b}$, respectively.

Fig. 5a shows that the depth of empty microchannel $(D)$ is approximately $250 \mu \mathrm{m}$ with an approximate roughness $\pm 12 \mu \mathrm{m}$. The roughness of channel, due to the manufacturing process is estimated from 10 measurements taken at different positions in one microchannel and for 10 empty channels at the fixed position (at the middle of channels). Fig. 5b represents the micro-channel with asphaltene deposits. The distance between deposition top and channel top is around $217 \mu \mathrm{m}$, which means the deposition thickness $(\delta)$ is appropriately $33 \mu \mathrm{m}$.
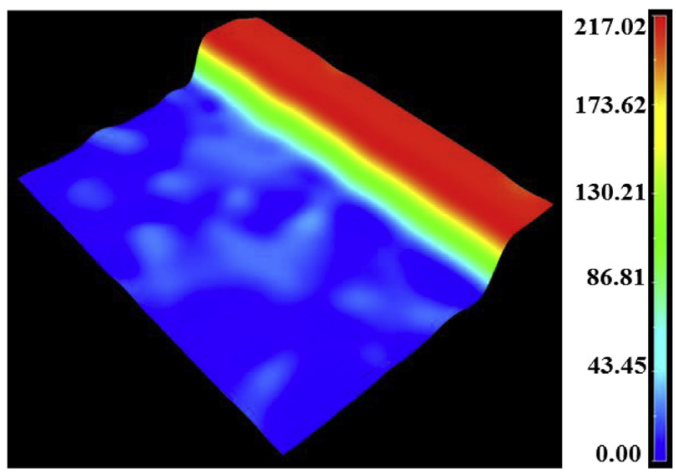

(b) Deposit thickness measurement represented by color difference $(\mu \mathrm{m})$

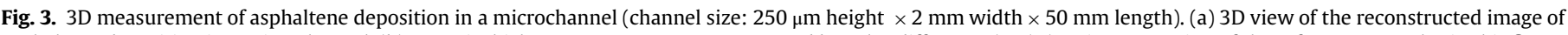

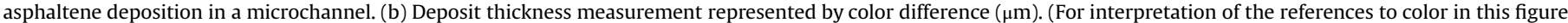
legend, the reader is referred to the web version of this article). 


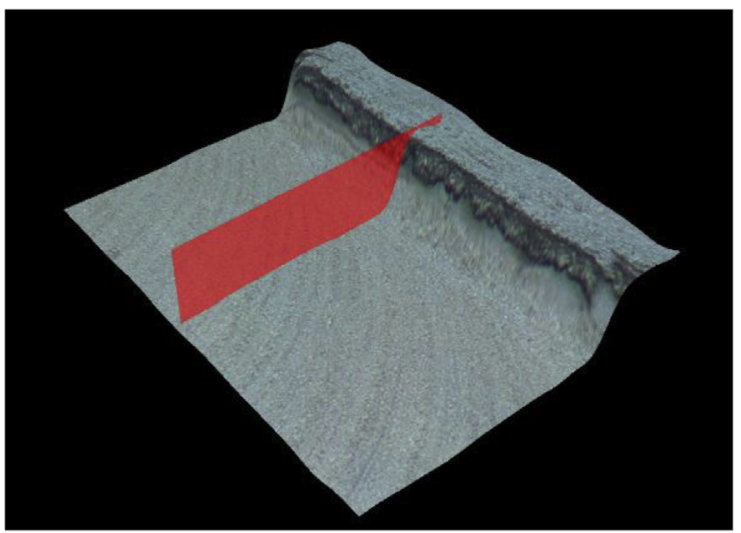

(a) Empty microchannel

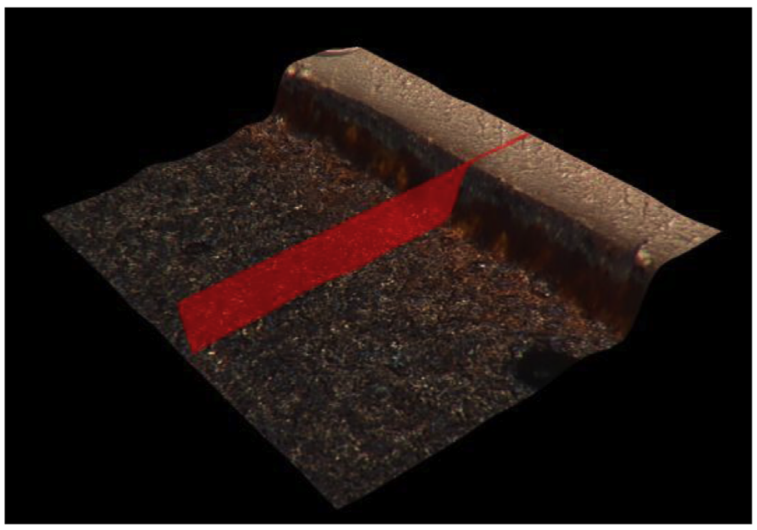

(b) Microchannel with deposits

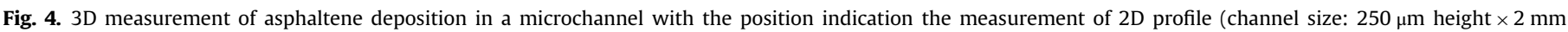

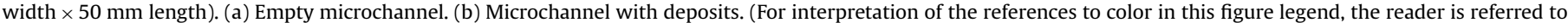
the web version of this article).

\subsection{Effect of injected volume on asphaltene deposit}

3D microscopy measurement is employed to study the influence of volume injection on deposit thickness by using two different experimental conditions, (i) varying the elapsed time of injection for a constant flow rate of $0.005 \mathrm{ml} / \mathrm{min}$ and (ii) changing the flow rates for a constant elapsed time of $10 \mathrm{~h}$. Both experimental results are illustrated in Fig. 6. For both cases the deposit thickness of asphaltene $(\delta)$ increases with the total injection volume $(V)$. It can be observed that the amount of asphaltene deposited on the microchannel walls is too low to be measured for the total volume injection less than $4 \mathrm{ml}$ and the microchannel is saturated (or blocked by the asphaltene particles) for total injection volume higher than $16 \mathrm{ml}$. The thickness range of the deposit is between 10 and $60 \mu \mathrm{m}$. These experimental results show that both experimental conditions obtain identical results in terms of the influence of the total injection volume.

Varying the elapsed time of injection for a constant flow rate of $0.005 \mathrm{ml} / \mathrm{min}$ shows that at a constant flow rate, the thickness of asphaltene deposit $(\delta)$ is growing in the microchannel. In this experiment the average velocity is $\bar{u}=5.5 \times 10^{-4} \mathrm{~m} / \mathrm{s}$. As it was expressed by Seifried et al. (2013) that the effect of flow rates on asphaltene deposition depended on the shear rate and therefore the magnitude of the average velocity. The range of velocity in this experiment is 10 times smaller than the velocity measured by Seifried et al. (2013) ( $\left.\bar{u}=6.4 \times 10^{-3} \mathrm{~m} / \mathrm{s}\right)$; however comparable experimental result in terms of the influence of volume injection on asphaltene deposit is obtained.

Changing the flow rates for a constant elapsed time of $10 \mathrm{~h}$ shows that the total injection volume is increased by increasing the flow rate of the fluid mixture. Therefore, even though the flow rate increases, asphaltene deposition is still increased linearly with the increasing total injection volume. The average velocities in this condition are ranging from $3.3 \times 10^{-4}$ to $8.9 \times 10^{-4} \mathrm{~m} / \mathrm{s}$, which are 10 times smaller than average velocity measured by Seifried et al. (2013).



(c) Empty microchannel with a maximum height of 250 $\mu \mathrm{m}$.

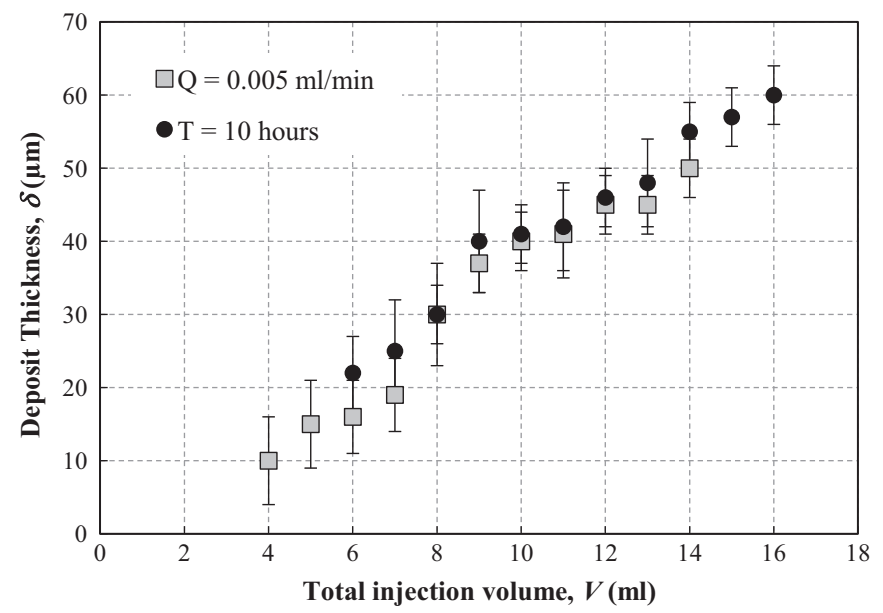

Fig. 6. Thickness measurement of Deposit thickness $(\delta)$ in terms of total injection volume $V$.

The normalized deposit thickness $\delta^{\prime}=\frac{\delta}{D}$ is presented versus Microchannel Volume Injection $\left(M V I=\frac{V}{V_{c}}\right)$ in Fig. 7, where $D=250 \mu \mathrm{m}$ and $V_{c}=250 \mu \mathrm{l}$ represent the depth and the total volume of the microchannel, respectively.

As showed by Fig. 7, the number of MVI is ranging from 160 to 640 and the normalized deposit thickness $\delta^{\prime}$ increases with MVI. With the increase of the capillary volume injection, the deposit thickness grows. Similar results are obtained by Lawal et al. (2012) even if the definition of normalized deposit thickness and experimental conditions are different. Measured experimental results show an approximate uniform deposition in the middle of the micro-channel. However it can be observed from Fig. 2a that the deposits along the micro-channel might not be uniform. Further research is needed to investigate the characteristics of asphaltene deposition in different locations along the micro-channel.

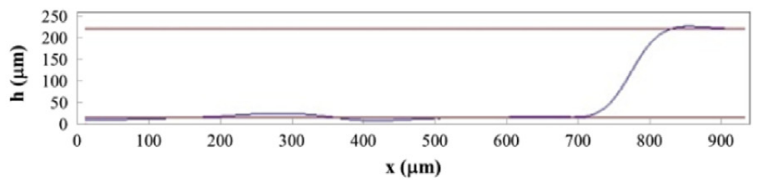

(d) Microchannel with deposits with a maximum height of $217 \mu \mathrm{m}$.

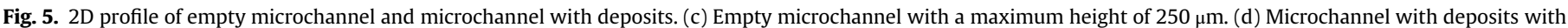
a maximum height of $217 \mu \mathrm{m}$. 


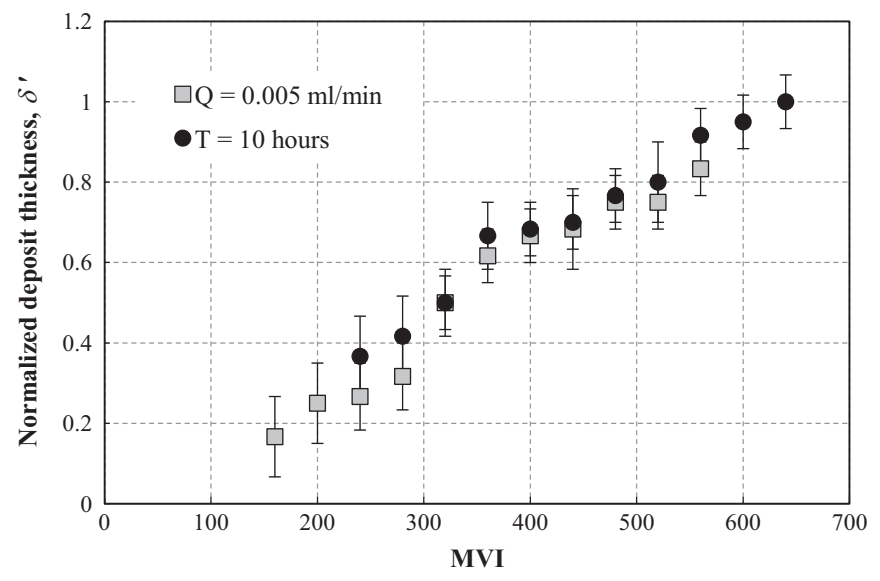

Fig. 7. Normalized deposit thickness $\left(\delta^{\prime}\right)$ as a function of Microchannel volume injection (MVI).

\section{Conclusions}

In this paper, experimental investigations of asphaltene deposition were carried out using transparent micro-channels in the laboratory condition. A new thickness measurement method for asphaltene deposits was presented using a 3D microscopy system. This method is based on reconstructed images to visualize the topology of the 3D asphaltene deposition layers. The thickness of the deposition layer is estimated and two-dimensional profile of the deposits is measured. This new approach permits direct measurements of asphaltene deposition layer. The influence of the volume injection was studied. Two experimental conditions were applied, consisting of varying elapsed time or changing flow rate. Results show that continuous asphaltene deposition can be represented by the change of deposition thickness, which can be directly measured by the 3D digital microscope. Obtained experimental results are validated using previous work of Lawal et al. (2012) and Seifried et al. (2013). The thickness of asphaltene deposits increases with the increase of the total injection volume. The measured thickness values range from 10 to $60 \mu \mathrm{m}$ when the total injection volume is changed from 4 to $16 \mathrm{ml}$.

The thickness measurement method provides a new idea to measure micron-size asphaltene deposition layers. The 3D microscopy technique will be used further to develop an empirical model of asphaltene deposition in microchannels.

\section{Acknowledgments}

The work is supported by a research Grant (RD006) from Abu Dhabi National Oil Company (ADNOC) through the Oil SubCommittee.

\section{References}

Akbarzadeh, K., Eskin, D., Ratulowski, J., Taylor, S., 2012. Asphaltene deposition measurement and modeling for flow assurance of tubings and flow lines. Energ. Fuel. 26 (1), 495-510.

Broseta, D., Robin, M., Savvidis, T., Féjean, C., Durandeau, M., Zhou, H., 2000. Detection of asphaltene deposition by capillary flow measurements, in: Proceedings of the SPE/DOE Improved Oil Recovery Symposium. Society of Petroleum Engineers. SPE-59294-MS.

Boek, E.S., Ladva, H.K., Crawshaw, J.P., Padding, J.T., 2008. Deposition of colloidal asphaltene in capillary flow: experiments and mesoscopic simulation. Energy Fuel 22 (2), 805-813.

Boek, E.S., Wilson, A.D., Padding, J.T., Headen, T.F., Crawshaw, J.P., 2009. Multi-scale simulation and experimental studies of asphaltene aggregation and deposition in capillary flow. Energy Fuel 24, 2361-2368.

Buckley, J.S., 2012. Asphaltene deposition. Energy Fuel 26, 4086-4090.

Hammami, A., Phelps, C.H., Monger-McClure, T., Little, T.M., 2000. Asphaltene precipitation from live oils: an experimental investigation of onset conditions and reversibility. Energy Fuel 14 (1), 14-18.

Hoepfner, M.P. Limsakoune, V., Chuenmeechao, V., Maqbool, T., Fogler, H.S., 2013. A fundamental study of asphaltene deposition. Energy Fuel 27 (2), 725-735.

Hu, C., Morris, J.E., Hartman, R.L., 2014. Microfluidic investigation of the deposition of asphaltenes in porous media. Lab Chip 14, 12.

Jamialahmadi, M., Soltani, B., Müller-Steinhagen, H., Rashtchian, D., 2009. Measurement and prediction of the rate of deposition of flocculated asphaltene particles from oil. Int. J. Heat Mass Transf. 52 (19), 4624-4634.

Lawal, K.A., Crawshaw, J.P., Boek, E.S., Vesovic, V., 2012. Experimental investigation of asphaltene deposition in capillary flow. Energy Fuel 26 (4), 2145-2153.

Nabzar, L., Aguiléra, M.E., 2008. The colloidal approach. A promising route for asphaltene deposition modelling. Oil Gas Sci. Technol. l'IFP 63, 21-35.

Papadimitriou, N.I., Romanos, G.E., Charalambopoulou, G.C., Kainourgiakis, M.E., Katsaros, F.K., Stubos, A.K., 2007. Experimental investigation of asphaltene deposition mechanism during oil flow in core samples. J. Pet. Sci. Eng. 57, 281-293.

Schneider, M.H., Sieben, V.J., Kharrat, A.M., Mostowfi, F., 2013. Measurement of asphaltenes using optical spectroscopy on a microfluidic platform. Anal. Chem. 85 (10), 5153-5160.

Seifried, C.M., Al Lawati, S., Crawshaw, J.P., Boek, E.S., 2013. Asphaltene Deposition in Capillary Flow, in: Proceedings of the SPE Annual Technical Conference and Exhibition. Society of Petroleum Engineers, SPE 166289.

Sheu, E.Y., Hammami, A., Marshall, A.G. (Eds.), 2007. Asphaltenes, heavy oils, and petroleomics vol. 1. Springer, New York.

Wang, J., Buckley, J.S., Creek, J.L., 2004. Asphaltene deposition on metallic surfaces J. Dispers. Sci. Technol. 25 (3), 287-298.

Zhuang, Y.G., Goharzadeh, A., Yap, Y.F., Chai, J.C., Mathew, N., Lin, Y.J.N., Vargas, F., Biswal, S.L., 2015a. Experimental investigation of asphaltene deposition in a transparent microchannel. TFESC, New York City, USA, August.

Zhuang, Y.G., 2015b. Asphaltene deposition in transparent mini- and micro-channels. The Petroleum Institute, Abu Dhabi, UAE. 